\title{
Intraspecific variation in larval size and its effects on juvenile lophophore size in four bryozoans
}

\author{
Ellen T. Kosman*, Bruno Pernet \\ Department of Biological Sciences, California State University - Long Beach, 1250 Bellflower Blvd, Long Beach, \\ California 90840, USA
}

\begin{abstract}
The quantity of maternal investment per offspring is related to maternal fitness and offspring performance. Some models suggest that maximum maternal fitness occurs when mothers produce offspring of a single optimal size (size being a proxy of maternal investment). However, there is substantial intraspecific variation in offspring size, especially in species with lecithotrophic larvae. For most species, the level at which this variation occurs (within vs. among brood) is unclear. We quantified variation in larval size within and among broods for 4 species of bryozoans with lecithotrophic larvae. Larval size was highly variable in all species, and the majority of the variation was found within broods for 3 of the 4 species. In all 4 species, sibling larvae varied up to 2 -fold in volume. Further, there were strong positive relationships between initial larval size and juvenile lophophore size for all 4 species. Lophophore size is related to feeding ability, so variation in larval size may result in variation in feeding ability among sibling juveniles. These results offer a probable mechanism for the positive relationship between initial larval size and colony growth rate in bryozoans.
\end{abstract}

KEY WORDS: Maternal investment · Offspring size $\cdot$ Larval quality $\cdot$ Bryozoa Resale or republication not permitted without written consent of the publisher

\section{INTRODUCTION}

The question of how much energy a mother should invest in each of her offspring is a fundamental issue in evolutionary biology. Maternal investment per offspring has important effects on the fitness of both mother and offspring (Bernardo 1996a, Marshall \& Uller 2007). For many marine organisms that produce lecithotrophic larvae, the organic material packaged in an egg or larva is the major energy source available to the offspring until after metamorphosis is complete. In such species, maternal investment is often positively correlated with offspring fitness, as offspring with more energy are able to metamorphose at a larger size, grow faster, and reach sexual maturity earlier then their less well-provisioned conspecifics (Moran \& Emlet 2001, Marshall \& Keough 2003, 2008a, Marshall et al. 2003, Marshall \& Bolton 2007). However, there is a trade-off between the number of offspring a mother can produce and the size (a commonly used proxy of maternal investment) of each offspring. Thus, while offspring fitness increases with increasing maternal in- vestment, maternal fitness begins to decline as overprovisioning offspring decreases the number of offspring a mother can produce (Smith \& Fretwell 1974). This tradeoff, in the context of other environmental factors that might affect juvenile fitness (e.g. the presence of size-specific predators or competitors), makes predicting optimal offspring size a difficult task.

Most models created to examine the evolution of offspring size predict that maximum maternal fitness occurs when mothers produce offspring of a single optimal size, allowing the mother to maximize the number of surviving offspring (Smith \& Fretwell 1974, Bernardo 1996a, Levitan 2000, Einum \& Fleming 2004). Such models often rely on the assumption that mothers have some way of predicting what environments their offspring will find themselves in and that the relationship between offspring size and performance is consistent across environments. However, mothers may not be able to accurately predict which environmental conditions their offspring will face, particularly in marine invertebrate species with dispersing larval stages (Palmer \& Strathmann 1981, Marshall \& Keough 
2006). In addition, there is evidence that the relationship between offspring size and performance is not consistent-as larger offspring may be selected against in certain environments (Marshall \& Keough 2004) - and that some advantages of larger larvae may be lost if metamorphosis is delayed for long periods of time (Wendt 1996, Marshall \& Keough 2006). In such cases, producing larger larvae is no guarantee that offspring will be more successful under all the environmental conditions that they may encounter. Given these uncertainties, producing a range of offspring sizes rather than producing offspring of a single size may decrease the variance around the mother's mean fitness (thus increasing her geometric mean fitness), as variability in offspring performance among reproductive events is reduced and the risk of total reproductive loss is avoided (Kaplan \& Cooper 1984, Philippi \& Seger 1989, Koops et al. 2003).

Indeed, a number of reports show that offspring vary in size not only among populations (George et al. 1990, Jones et al. 1996) and among broods within populations (Kaplan \& King 1997, Berg et al. 2001), but also within broods (Phillips 2007, Marshall \& Keough 2008a). The extent of this variation can be quite large (Kaplan 1998, Marshall \& Keough 2008b). However, most studies that have examined variation in offspring size in marine invertebrates quantify variation at a single hierarchical level (e.g. among populations) and make no attempt to determine where the majority of the variation in offspring size occurs. Such data are essential to understanding how populations respond to selection. The distribution of intraspecific variation in offspring size may influence the direction and rate of offspring size evolution, particularly if such variation is heritable and great enough to cause differences in performance among siblings (Bernardo 1996b, Kaplan 1998). In the present study, we describe variation in offspring size within populations and within broods of 4 species of marine bryozoans. We also determined if variation in offspring size might affect juvenile lophophore size, a relationship that would offer a mechanistic explanation as to why offspring size is positively correlated with several aspects of adult performance in bryozoans (Marshall et al. 2003, Marshall 2005, Dias \& Marshall 2010).

Bryozoans are colonial, hermaphroditic organisms that are common members of many marine hard substratum communities and are especially common in fouling communities. Most species produce lecithotrophic coronate larvae that are released early in the day (Kosman \& Pernet 2009) and settle within a few hours after release (Mawatari 1951, Ryland 1974). Larvae can be collected easily from adults in the laboratory by manipulating light cues and can be induced to settle using chemical cues (Wendt \& Woollacott 1995). Larval size offers a reliable, non-destructive method of estimating maternal investment per offspring, as size is positively correlated to organic content (Wendt 2000) and has been linked to performance (e.g. colony growth rate and age at sexual maturity; Marshall et al. 2003, Marshall 2005) in later life history stages. After metamorphosis of coronate larvae, the resulting juveniles possess a single lophophore with which they feed on suspended particles. We measured lophophore volume as an indicator of juvenile feeding performance, as bryozoan feeding rates are positively related to lophophore size (specifically, lophophore height and spread; Best \& Thorpe 1986a,b). If larval size and lophophore size are related, differences in lophophore size, and thus feeding ability, might explain why colonies that originate from larger larvae grow faster and reach sexual maturity sooner than colonies derived from smaller larvae.

\section{MATERIALS AND METHODS}

Variation in larval size. We quantified variation in larval size within and among broods in 4 species of bryozoans common in fouling communities in southern California. Individual colonies of 3 of these species were collected directly from floating docks in Alamitos Bay, Long Beach, California. We collected 10 colonies of Bugula californica and 10 colonies of Watersipora subtorquata between January and April 2007. A total of 10 colonies of Cryptosula pallasiana were collected in June and July 2008 and in March 2009. For these 3 species, we made efforts to ensure that each collected colony was a single genetic individual. $B$. californica typically grew as isolated upright colonies; we traced each of these to its basal attachment point. We removed a single upright lobe from each colony of the crenulated bryozoan $W$. subtorquata. As it was unclear if the zooids on both sides of these lobes were derived from the same larva, one side of the lobe was cleaned of zooids with a needle. For the encrusting bryozoan C. pallasiana, we collected only isolated, disc-shaped colonies that appeared likely to be derived from a single, settled larva.

Colonies of the fourth species, Bugula neritina, often grew in dense mats and thus were difficult to trace back to a single attachment point. To ensure that the adult colonies we studied did not comprise several genotypes, we reared individual colonies from the larval stage to sexual maturity in the field. In March 2007, we collected 8 colonies of B. neritina from Alamitos Bay and held them overnight in a darkened flow-through aquarium. After exposing the darkadapted colonies to bright light to induce larval release, we haphazardly collected larvae for settlement on 60 plastic petri dishes. Each dish was filled with 
seawater containing $15 \mathrm{mM}$ excess $\mathrm{KCl}$ to induce larval settlement. After settlement, the metamorphosing larvae were submerged in fresh seawater and allowed to complete metamorphosis for $6 \mathrm{~d}$ at $20^{\circ} \mathrm{C}$. The petri dishes were then placed in 4 acrylic racks (each rack holding 15 dishes) and hung off the side of a floating dock in Alamitos Bay, 1 m below the surface. Growth to sexual maturity took approximately $7 \mathrm{wk}$.

For all 4 species, larvae were obtained by placing the parent colonies into a darkened flow-through aquarium for $\sim 48 \mathrm{~h}$ and then exposing each colony individually to a bright light. Larvae released from each colony were preserved in $4 \%$ formalin in seawater for later size measurements.

Larval size was estimated as volume. Twenty preserved larvae from each colony were haphazardly chosen for measurement. One colony of Cryptosula pallasiana released only 19 larvae; in this case all larvae were measured. All larvae were photographed in the same orientation, by positioning them with their ciliated groove upwards (Marshall et al. 2003). Larvae of Bugula californica were roughly spherical in shape, so larval volume was estimated from photographs by measuring the width of the larva perpendicular to the ciliated groove and using that 'diameter' to calculate the volume of a sphere. Larvae of the other 3 species were barrel-shaped; their volumes were estimated by measuring the width of the larva (perpendicular to the ciliated groove) and the length of the larva (along the ciliated groove). Those 2 measurements were then used to calculate the volume of a cylinder.

The mean larval volume for each species and the coefficient of variation (CV) of larval volumes for each brood were calculated for all 4 species. For each species, an ANOVA was used to determine if the majority of the variation in larval volumes was found within or among broods (Sokal \& Rohlf 1981). The data were tested for normality and homogeneity prior to running the ANOVA. Brood CVs were compared among species using ANOVA and post-hoc Tukey comparison test.

Effects of larval size on juvenile lophophore size. To determine how larval size affected juvenile lophophore size within each species, larvae were allowed to metamorphose, and the relationship between their initial volume and subsequent lophophore size was examined. Colonies of the 4 bryozoan species were collected from Alamitos Bay in 2008 (April to June). The colonies were placed in a darkened flow-through aquarium for $\sim 48 \mathrm{~h}$, then exposed to a bright light to induce larval release. In order to increase the size range of larvae studied, we actively selected larvae of a wide size range for measurement. No single parental colony contributed more than 6 larvae to the analysis.

Larval size was estimated from videotaped images of swimming larvae. Larvae in a drop of seawater were videotaped using a Nikon 80i compound microscope equipped with a $40 \times$ objective lens and a Hitachi II video camera. For each larva, a single video frame (with the larva oriented with its ciliated groove upwards) was used to estimate larval volume, using the methods described above. After videotaping, larvae were settled on biofilmed egg membranes (Reed \& Cloney 1982) in individual dishes containing seawater with $15 \mathrm{mM}$ excess $\mathrm{KCl}$. After settlement, larvae were held in an incubator at $20^{\circ} \mathrm{C}$ in fresh seawater until metamorphosis was completed and the ancestrula lophophore was formed.

To estimate lophophore volume, juveniles were relaxed in a 1:1 mixture of seawater and $7.5 \% \mathrm{MgCl}_{2}$ and photographed in side view with their lophophores extended. Lophophore volume was estimated using measurements obtained from photographs and the equation:

$$
\text { Volume }=\pi h\left(a^{2}+a b+b^{2}\right) / 12
$$

where $a$ is the diameter of the lophophore crown, $b$ is the diameter of the base, and $h$ is the height of the lophophore (Wendt 1996). The relationship between initial larval volume and lophophore volume for each species was examined using reduced major axis (RMA) regression (Quinn \& Keough 2002).

\section{RESULTS}

\section{Variation in larval size}

There was substantial variation in larval volume among species, within species, and within broods. Watersipora subtorquata and Bugula neritina released the largest larvae, with average volumes of $0.0288 \pm$ $0.0050 \mathrm{~mm}^{3}( \pm \mathrm{SD})$ and $0.0247 \pm 0.0032 \mathrm{~mm}^{3}$, respectively. Cryptosula pallasiana released larvae of an average volume of $0.0086 \pm 0.0001 \mathrm{~mm}^{3}$, while $B$. californica released the smallest larvae, with an average volume of $0.0013 \pm 0.0003 \mathrm{~mm}^{3}$ (Table 1). There was great variation in larval volume within species, with most species releasing larvae that varied up to 3-fold in volume (Table 1).

The majority of the variation in larval volume was found within broods for 3 of the 4 species (Table 1). For Watersipora subtorquata, $76.08 \%$ of the total variation in larval size was found within broods. In Bugula neritina, larval size variation was distributed approximately equally within and among broods, with $54.19 \%$ of the variation found within broods. In Cryptosula pallasiana, $68.48 \%$ of the variation in larval size was found within broods. In B. californica, $92.06 \%$ of the total observed variation in larval size was within-brood variation. 
Table 1. Mean larval volume $( \pm \mathrm{SD})$ released from a population, larval volume and brood coefficient of variation $(\mathrm{CV})$ ranges for a population, and the percentage of variation attributed to within-brood causes for each of the 4 bryozoan species

\begin{tabular}{|c|c|c|c|c|}
\hline \multirow{2}{*}{ Species } & \multicolumn{2}{|c|}{ - Larval volume } & \multirow{2}{*}{$\begin{array}{c}\text { Brood CV range } \\
(\%)\end{array}$} & \multirow{2}{*}{$\begin{array}{c}\% \text { Variation } \\
\text { within broods }\end{array}$} \\
\hline & Mean & Range within population & & \\
\hline Watersipora subtorquata & $0.0288 \pm 0.0050$ & $0.0148-0.0410$ & $12.12-20.66$ & 76.08 \\
\hline Bugula neritina & $0.0247 \pm 0.0032$ & $0.0180-0.0335$ & $6.80-14.57$ & 54.19 \\
\hline Cryptosula pallasiana & $0.0086 \pm 0.0001$ & $0.0059-0.0131$ & $8.95-19.69$ & 68.48 \\
\hline Bugula californica & $0.0013 \pm 0.0003$ & $0.0008-0.0020$ & $13.00-21.83$ & 92.06 \\
\hline
\end{tabular}

CVs in larval volume were calculated for each brood spawned and their means compared among species using ANOVA and a post-hoc Tukey comparison test. These data met the assumptions of ANOVA. There was a significant difference in brood CVs among species (ANOVA: $\mathrm{p}<0.001, F=21.24, \mathrm{df}=45$ ). Brood CVs for Bugula neritina were the lowest of the 4 species, and Cryptosula pallasiana's average brood CV was lower than B. californica's (Fig. 1). Brood CVs for Watersipora subtorquata ranged from 12.12 to $20.66 \%$, representing a 1.5- to 1.9-fold difference between the largest and smallest larva released by a single colony. B. neritina's brood CVs ranged from 6.80 to $14.57 \%$, representing only a 1.3- to 1.6-fold difference in larval sizes found within a brood. In C. pallasiana, brood CVs ranged from 8.95 to $19.69 \%$, representing a 1.5 - to 2.2 -fold difference in larval sizes released by a single colony. Finally, brood CVs ranged from 13.00 to $21.83 \%$ in B. californica, representing a 1.6- to 2.1-fold difference in larval sizes found within a brood (Table 1).

\section{Effects of larval size on juvenile lophophore size}

Completion of metamorphosis (defined as time to formation of a functional juvenile lophophore) took approximately 2 d for Bugula californica and B. neritina,

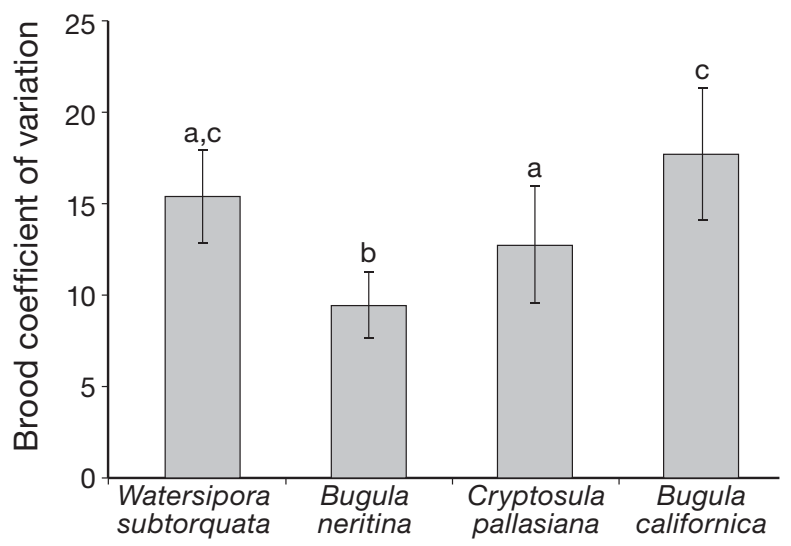

Fig. 1. Brood coefficients of variance (CV) for the 4 species of bryozoans. Significant differences among mean brood CVs are denoted with differing letters. Error bars are \pm SD
$4 \mathrm{~d}$ for Cryptosula pallasiana, and $5 \mathrm{~d}$ for Watersipora subtorquata. There was substantial intraspecific variation in juvenile lophophore volume in all 4 species, with at least a 5-fold range in lophophore volume among conspecifics. Lophophore volumes ranged from 0.021 to $0.109 \mathrm{~mm}^{3}$ for $W$. subtorquata, 0.003 to $0.062 \mathrm{~mm}^{3}$ for B. neritina, 0.006 to $0.043 \mathrm{~mm}^{3}$ for C. pallasiana, and 0.003 to $0.017 \mathrm{~mm}^{3}$ for B. californica. Further, RMA regression showed that in all 4 species variation in lophophore volume was positively related to initial larval volume (Fig. 2).

\section{DISCUSSION}

In all 4 species we examined, there was substantial variation in larval size within individual broods. Previously calculated CVs for Bugula neritina (Marshall \& Keough 2008b, Marshall et al. 2008) fell within the range calculated by the present study. However, the previously published values were based on an unknown number of individuals, and in the present study we found that within-brood CV varied among individual colonies (Table 1). The within-brood CVs for larval size calculated for these bryozoans were similar to those found in studies of diverse other marine invertebrates, including mussels, starfish, and shrimp (McEdward \& Carson 1987, Clarke 1993, Phillips 2007 , Marshall \& Keough 2008b), suggesting that substantial variability in offspring size found within broods is taxonomically widespread.

We partitioned the distribution of variance in larval size, something that has been done only rarely in marine animals. In the 4 species we studied, 54 to $92 \%$ of the total variation in larval size observed was found within broods; in 3 of these species (Watersipora subtorquata, Cryptosula pallasiana, and Bugula californica), within-brood variation accounted for over $68 \%$ of the total variation in larval size. One of the few comparable datasets available provides a similar result: Marshall \& Keough (2008a) reported that $66 \%$ of the variation in larval size in Australian populations of $W$. subtorquata occurred within broods. In our study, $76 \%$ of the variation in larval size in W. subtorquata was found within broods. 


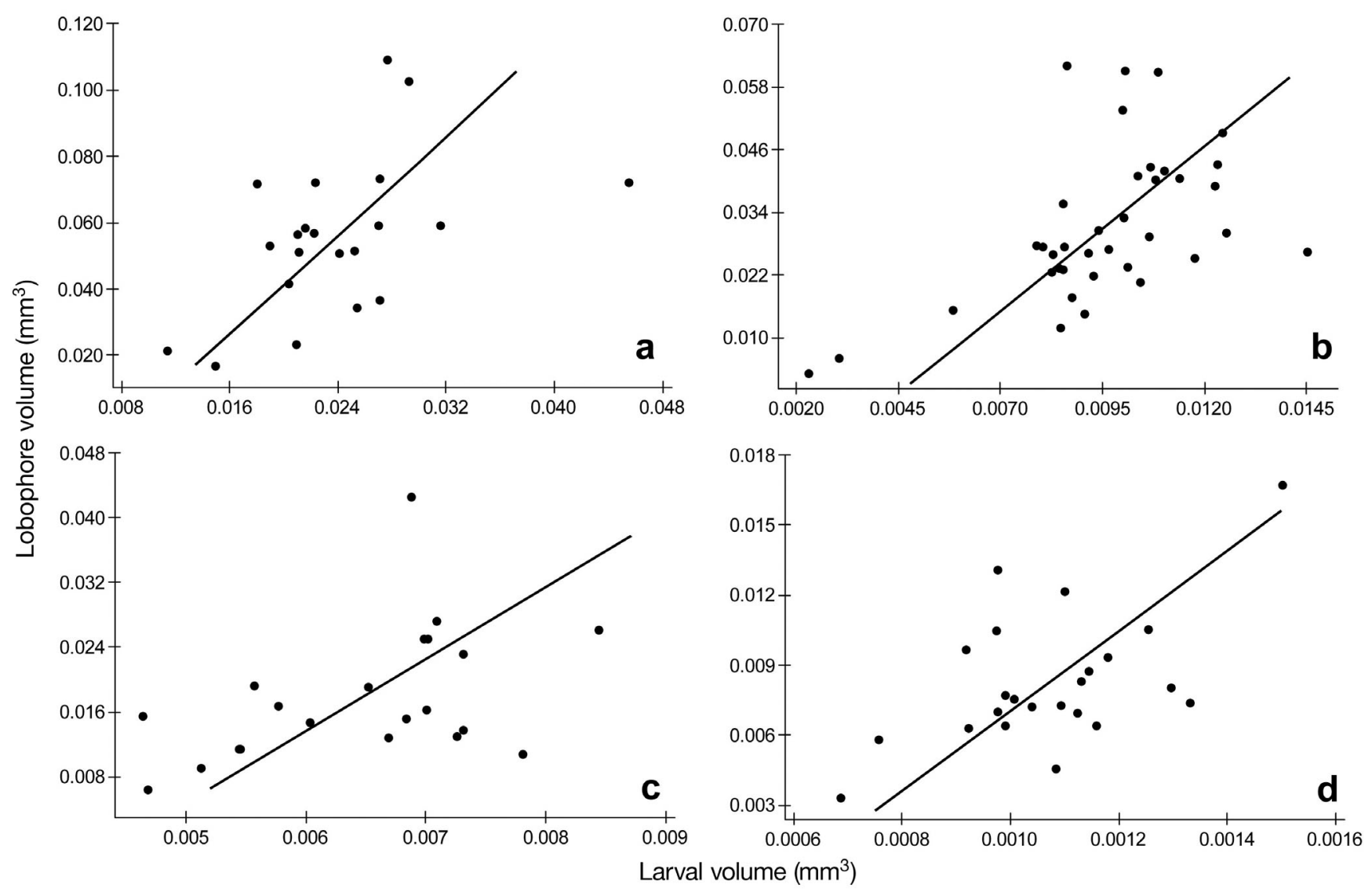

Fig. 2. Relationship between larval volume and juvenile lophophore volume in the bryozoans (a) Watersipora subtorquata, (b) Bugula neritina, (c) Cryptosula pallasiana, and (d) Bugula californica. A significant positive relationship between larval volume and juvenile lophophore volume was found in all 4 species. Note the difference in scale for all axes

It is unclear to what extent within-brood variation in offspring size varies among populations or seasons, although preliminary data suggest that the amount of variation found within broods fluctuated very little over a 2 yr period within a population of Bugula neritina (E. T. Kosman unpubl. data). Additionally, the similarity between our results and those of Marshall \& Keough (2008a) suggest that substantial within-brood variation in offspring size is common among populations of Watersipora subtorquata. Our results for the remaining species suggest that substantial within-brood variation in offspring size may be widespread among bryozoans with lecithotrophic larvae; however, more species need to be sampled to determine if this is truly the case. It is not yet clear whether other marine invertebrates with lecithotrophic larval stages exhibit similar patterns of withinbrood variation in offspring size. Data available from fishes suggest that only a small fraction ( $3 \%$ for salmon) of intraspecific variation in offspring size is found within broods (Berg et al. 2001, Einum \& Fleming 2004).

We also identified substantial within-population variation in juvenile lophophore size for larvae that were forced to settle soon after release. Juvenile lophophores varied in volume $\sim 5.1$-fold in both Watersipora subtorquata and Bugula californica, 6.7-fold in Cryptosula pallasiana, and 20.6-fold in B. neritina (however, removal of 2 extremely small outliers reduced this range to 5.3-fold for B. neritina). Even with those 2 outliers excluded, the range in juvenile lophophore volume that we observed within a population of $B$. neritina far exceeds the variation in lophophore volume observed in previous experiments on the effects of the length of the larval planktonic period on juvenile quality. Larvae of $B$. neritina forced to swim for $28 \mathrm{~h}$ before metamorphosis produced juveniles whose lophophores were about half the volume of larvae that were allowed to settle soon after release (Wendt 1996); thus, lophophore volume varied only 2-fold as a function of larval swimming duration. Our results suggest that natural variation in larval size within populations (and presumably within broods) of $B$. neritina might be sufficient to mask more subtle treatment effects in such experiments. Accounting for variation in initial larval size in experiments such as this might greatly increase the accuracy of estimates of the magnitude of treatment effects. 
The high variation in lophophore size appeared to be due to variation in initial larval size, as there was a significant positive relationship between larval size and lophophore size for all species. As feeding rates increase with increasing lophophore size (Best \& Thorpe 1986a,b), larger juveniles would be more effective at capturing and processing food than their smaller siblings. It is likely that the variability in the size of juvenile lophophores described here would have consequences for the feeding abilities of sibling offspring. Based on the regression equations calculated for each species, we estimate that the variation in larval size within a brood could result in a 1.7- to 2.7-fold difference in juvenile lophophore volume among sibling Watersipora subtorquata, a 1.3- to 1.9-fold difference among sibling Bugula neritina, a 2.5- to 5.9-fold difference among sibling Cryptosula pallasiana, and a 2.2- to 4.0-fold difference among sibling $B$. californica. These differences in juvenile lophophore size and subsequent feeding rates may explain why colonies of $B$. neritina and $W$. subtorquata that originate from large larvae have higher growth rates and reach sexual maturity sooner than colonies that originate from smaller larvae (Marshall et al. 2003, Marshall \& Keough 2004).

Further studies are needed to determine the mechanisms underlying within-brood variation in offspring size in bryozoans. One possibility is that maternal provisioning is carried out primarily by the parental zooid. If zooids within a colony vary in feeding environment, e.g. with some zooids near the base of an upright colony and others near the growing tips, then variation in zooid nutritional environment may lead to within-brood variation in larval size. If this were the case, one might expect greater variation in larval size in upright, branching colonies versus encrusting colonies, as feeding environment seems likely to vary more in the former type of colony. However, we saw no trend associated with colony morphology in the amount of within-brood variability in the 4 species we examined: upright colonies (those of Bugula californica and B. neritina) had similar brood CVs to those of encrusting colonies (Cryptosula pallasiana and Watersipora subtorquata; Table 1). Thus, among-zooid differences in terms of food environment seem unlikely to be fully responsible for the wide range in offspring sizes produced by the colonies we observed. Some data suggest that the amount of variation in offspring sizes produced by colonies of $B$. neritina is not fixed and can change in response to stressors, such as colony wounding (Crean \& Marshall 2009). However, the mechanisms underlying such plasticity in within-brood variation in larval size are currently unknown.

As there is a positive relationship between larval size and juvenile feeding ability in the bryozoans studied, it may seem that producing larger larvae would maxi- mize the mother's fitness, despite the decrease in the number of larvae the mother produces. However, there is evidence in bryozoans that larger offspring may be selected against in certain environments, possibly due to size-selective predation or low conspecific competition (Marshall \& Keough 2004, Allen et al. 2008), and that some advantages that larger larvae possess, e.g. producing a larger lophophore, may be lost if metamorphosis is delayed for long periods of time (Wendt 1996). Additionally, because the parental colony is sessile and unable to detect nearby environments, whereas the larva is motile and may disperse to these novel environments, the parent colony may not be able to accurately predict what environmental conditions the offspring will face. Because of this, it is possible that high within-brood variation is a useful mechanism to ensure that at least some suitable larvae are produced (Marshall et al. 2008).

Many studies have used verbal and mathematical arguments to suggest that within-brood variation in offspring size might be adaptive (Kaplan \& Cooper 1984, Philippi \& Seger 1989, Marshall et al. 2008), but few studies have empirically tested these arguments. Whether the within-brood variation in offspring size reported in the present study represents an adaptive response to provision offspring for unpredictable environments remains to be tested. However, our results show that considerable within-brood variation in offspring size exists and suggest that such variation can have an effect on later life history stages via its effect on lophophore size and subsequent feeding ability. Accounting for this substantial intraspecific variation in maternal investment per offspring should greatly increase the explanatory power of studies that aim to identify other factors (e.g. length of the planktonic period) that may be affected by larval size.

Acknowledgements. We thank A. Carrillo and J. Kalman for their comments on the manuscript. Funding was provided by grants to E.T.K. by the Society for Integrative and Comparative Biology and the Southern California Tuna Club. Additional support was provided by the Department of Biological Sciences and the College of Natural Sciences and Mathematics at California State University-Long Beach.

\section{LITERATURE CITED}

Allen RM, Buckley YM, Marshall DJ (2008) Offspring size plasticity in response to intraspecific competition: an adaptive maternal effect across life-history stages. Am Nat 171:225-237

> Berg OK, Hendry AP, Svendsen B, Bech C, Arnekleiv JV, Lohrmann A (2001) Maternal provisioning of offspring and the use of those resources during ontogeny: variation within and between Atlantic salmon. Funct Ecol 15:13-23 Bernardo J (1996a) The particular maternal effect of propag- 
ule size, especially egg size: patterns, models, quality of evidence and interpretations. Am Zool 36:216-236

Bernardo J (1996b) Maternal effects in animal ecology. Am Zool 36:83-105

- Best MA, Thorpe JP (1986a) Effects of food particle concentration of feeding current velocity in six species of marine Bryozoa. Mar Biol 93:255-262

Best MA, Thorpe JP (1986b) Feeding-current interactions and competition for food among the bryozoan epiphytes of Fucus serratus. Mar Biol 93:371-376

Clarke A (1993) Egg size and egg composition in polar shrimps (Caridea; Decapoda). J Exp Mar Biol Ecol 168: 189-203

Crean AJ, Marshall DJ (2009) Coping with environmental uncertainty: dynamic bet hedging as a maternal effect. Philos Trans R Soc Lond B 364:1087-1096

Dias GM, Marshall DJ (2010) Does the relationship between offspring and performance change across the life-history? Oikos 119:154-162

Einum S, Fleming IA (2004) Environmental unpredictability and offspring size: conservative versus diversified bethedging. Evol Ecol Res 6:443-455

> George SB, Cellario C, Fenaux L (1990) Population differences in egg quality Arbacia lixula (Echinodermata: Echinoidea) proximate composition of eggs and larval development. J Exp Mar Biol Ecol 141:107-118

Jones HL, Todd CD, Lambert WJ (1996) Intraspecific variation in embryonic and larval traits of the dorid nudibranch mollusc Adalaria proxima (Alder and Hancock) around the northern coasts of the British Isles. J Exp Mar Biol Ecol 202:29-47

Kaplan RH (1998) Maternal effects, developmental plasticity, and life history evolution: an amphibian model. In: Mousseau TA, Fox CW (eds) Maternal effects as adaptations, Vol 1. Oxford University Press, New York, NY, p 244-257

Kaplan RH, Cooper WS (1984) The evolution of developmental plasticity in reproductive characteristics: an application of the 'adaptive coin-flipping' principle. Am Nat 123: 393-410

Kaplan RH, King EG (1997) Egg size is a developmentally plastic trait: evidence from long term studies in the frog Bombina orientalis. Herpetologica 53:149-165

Koops MA, Hutchings JA, Adams BK (2003) Environmental predictability and the cost of imperfect information: influences on offspring size variability. Evol Ecol Res 5:29-42

Kosman ET, Pernet B (2009) Diel variation in the sizes of larvae of Bugula neritina in field populations. Biol Bull 216: 85-93

Levitan DR (2000) Optimal egg size in marine invertebrates: theory and phylogenetic analysis of the critical relationship between egg size and development time in echinoids. Am Nat 156:175-192

Marshall DJ (2005) Geographical variation in offspring size effects across generations. Oikos 108:602-608

Marshall DJ, Bolton TF (2007) Effects of egg size on the development time of non-feeding larvae. Biol Bull 212:6-11

Marshall DJ, Keough MJ (2003) Effects of settler size and density on early post-settlement survival of Ciona intestinalis in the field. Mar Ecol Prog Ser 259:139-144

Editorial responsibility: Hans Heinrich Janssen, Oldendorf/Luhe, Germany
Marshall DJ, Keough MJ (2004) Variable effects of larval size on post-metamorphic performance in the field. Mar Ecol Prog Ser 279:73-80

- Marshall DJ, Keough MJ (2006) Complex life cycles and offspring provisioning in marine invertebrates. Integr Comp Biol 46:643-651

> Marshall DJ, Keough MJ (2008a) The relationship between offspring size and performance in the sea: variation over space and time. Am Nat 171:214-224

Marshall DJ, Keough MJ (2008b) The evolutionary ecology of offspring size in marine invertebrates. Adv Mar Biol 53: $1-60$

> Marshall DJ, Uller T (2007) When is a maternal effect adaptive? Oikos 116:1957-1963

> Marshall DJ, Bolton TF, Keough MJ (2003) Offspring size affects the post-metamorphic performance of a colonial marine invertebrate. Ecology 84:3131-3137

Marshall DJ, Bonduriansky R, Bussiere LF (2008) Offspring size variation within broods as a bet-hedging strategy in unpredictable environments. Ecology 89:2506-2517

Mawatari S (1951) The natural history of a common fouling bryozoan, Bugula neritina (Linnaeus). Misc Rep Res Inst Nat Resour 20:47-54

McEdward L, Carson S (1987) Variation in egg organic content and its relationship with egg size in the starfish Solaster stimpsoni. Mar Ecol Prog Ser 37:159-169

Moran AL, Emlet RB (2001) Offspring size and performance in variable environments: field studies on a marine snail. Ecology 82:1597-1612

Palmer AR, Strathmann RR (1981) Scale of dispersal in varying environments and its implications for life histories of marine invertebrates. Oecologia 48:308-318

Philippi T, Seger J (1989) Hedging one's evolutionary bets, revisited. Trends Ecol Evol 4:41-44

Phillips NE (2007) High variability in egg size and energetic content among intertidal mussels. Biol Bull 212:12-19

Quinn G, Keough M (2002) Experimental design and data analysis for biologists. Cambridge University Press, Cambridge

Reed CG, Cloney RA (1982) The settlement and metamorphosis of the marine bryozoan Bowerbankia gracilis (Ctenostomata: Vesicularioidea). Zoomorphology 101: 103-132

Ryland JS (1974) Behaviour, settlement, and metamorphosis of bryozoan larvae: a review. Thalassia Jugosl 10:239-263

Smith CC, Fretwell SD (1974) The optimal balance between size and number of offspring. Am Nat 108:499-506

Sokal RR, Rohlf FJ (1981) Biometry: the principles and practice of statistics in biological research. WH Freeman, San Francisco, CA

Wendt DE (1996) Effect of larval swimming duration on success of metamorphosis and size of the ancestrular lophophore in Bugula neritina (Bryozoa). Biol Bull 191:224-233

> Wendt DE (2000) Energetics of larval swimming and metamorphosis in four species of Bugula (Bryozoa). Biol Bull 198:346-356

- Wendt DE, Woollacott RM (1995) Induction of larval settlement by $\mathrm{KCl}$ in three species of Bugula (Bryozoa). Invertebr Biol 114:345-351

Submitted: June 15, 2010; Accepted: February 21, 2011 Proofs received from author(s): May 3, 2011 